\title{
Effects of NRF1 on steroidogenesis and apoptosis in goat luteinized granulosa cells
}

\author{
Guo-Min Zhang ${ }^{1,2}$, Ming-Tian Deng ${ }^{2}$, Zhi-Hai Lei ${ }^{1}$, Yong-Jie Wan², Hai-Tao Nie' ${ }^{2}$, Zi-Yu Wang², \\ Yi-Xuan Fan², Feng Wang ${ }^{2}$ and Yan-Li Zhang ${ }^{2}$ \\ ${ }^{1}$ College of Veterinary Medicine, Nanjing Agricultural University, Nanjing, China and ${ }^{2}$ Jiangsu Livestock Embryo \\ Engineering Laboratory, Nanjing Agricultural University, Nanjing, China
}

Correspondence should be addressed to Y-L Zhang; Email: zhangyanli@njau.edu.cn

\begin{abstract}
During goat follicular development, abnormal expression of nuclear respiratory factor 1 (NRF1) in granulosa cells may drive follicular atresia with unknown regulatory mechanisms. In this study, we investigated the effects of NRF1 on steroidogenesis and cell apoptosis by overexpressing or silencing it in goat luteinized granulosa cells (LGCs). Results showed that knockdown of NRF1 expression significantly inhibited the expression of STAR and CYP19A1, which are involved in sex steroid hormones synthesis, and led to lower estrogen levels. Knockdown of NRF1 resulted in an increased percentage of apoptosis, probably due to the release of cytochrome $\mathrm{c}$ from mitochondria, accompanied by upregulating mRNA and protein levels of apoptosis-related markers BAX, caspase 3 and caspase 9. These data indicate that NRF1 might be related with steroidogenesis and cell apoptosis. Furthermore, NRF1 silence reduced mitochondrial transcription factor A (TFAM) transcription activity, mtDNA copy number and ATP level. Simultaneously, knockdown of NRF1 suppressed the transcription and translation levels of SOD, GPx and CAT, decreased glutathione level and increased 8-OHdG level. However, the overexpression of NRF1 in LGCs or gain of TFAM in NRF1 silenced LGCs increased the expression of genes involved in mitochondrial function and biogenesis, and elevated the antioxidant stress system and steroids synthesis. Taken together, aberrant expression of NRF1 could induce mitochondrial dysfunction and disturb the cellular redox balance, which lead to disturbance of steroid hormone synthesis, and trigger LGC apoptosis through the mitochondria-dependent pathway. These findings will be helpful for understanding the role of NRF1 in goat ovarian follicular development and atresia.

Reproduction (2017) 154 111-122
\end{abstract}

\section{Introduction}

In mammals, only a few follicles will ovulate, and more than $99 \%$ of follicles will undergo atresia during follicular growth and development (Asselin et al. 2000). Follicular atresia is normally considered to be a hormonally controlled apoptotic process (Kaipia \& Hsueh 1997), which was regulated by endocrine and paracrine changes. Among which granulosa cell (GC) apoptosis is considered as a main mechanism for follicular atresia (Asselin et al. 2000). GC apoptosis is a morphologically and biochemically distinct process inducted and executed via several signaling pathways (Lin et al. 2012). Some factors known to regulate GC apoptosis include reproductive hormones, cytokines and apoptotic related factors (Matsuda et al. 2012), while the intracellular regulation of goat GC apoptosis is unclear.

Mitochondria play central roles in the initiation of apoptosis triggered by intrinsic death signals (Zamzami \& Kroemer 2001). It has been reported that mitochondrial dysfunction in GCs results in follicular atresia (Glister et al. 2014). Nuclear respiratory factor 1
(NRF1), as a major transcription factor, is involved in mitochondrial biogenesis, signal transduction and protein synthesis (Zhang \& Manning 2015). Downregulation of NRF1 contributes to mitochondrial dysfunction (Wang et al. 2006), while overexpression of NRF1 could protect neuronal cells from $\mathrm{MPP}^{+}$-induced mitochondrial dysfunction (Piao et al. 2012). Moreover, our previous study has shown that goat GCs have a reduced NRF1 expression in atretic follicles compared with healthy follicles (Zhang et al. 2015). Despite these findings, the regulation of NRF1 in GC apoptosis and follicular atresia remains to be elucidated, especially in goat.

GCs constitute the vast majority of follicular cells in mammalian ovary, and function as steroid synthesis during follicular development (Sanchez et al. 2016). Sex steroid hormones progesterone $\left(\mathrm{P}_{4}\right)$ and estradiol $\left(\mathrm{E}_{2}\right)$ participate in regulating ovarian function (Drummond 2006), and act as antioxidant protecting follicles from oxidative stress and atresia (Jain et al. 2013, Mahmoodi et al. 2015). In addition, $\mathrm{E}_{2}$-induced DNA synthesis in MCF-7 breast cancer cells depends on 
mitochondrial oxidant signaling to NRF1 (Okoh et al. 2015), knockdown of NRF1 blocks $E_{2}$ stimulation of mitochondrial biogenesis and activity (Mattingly et al. 2008). These studies indicate NRF1 may be involved in the regulation of steroidogenesis, oxidative stress and cell apoptosis.

To provide insights into the role of NRF1 in regulating goat follicular atresia, we investigated the effects of NRF1 on steroidogenesis, mitochondrial function and cell apoptosis through overexpressing or silencing it in luteinized granulosa cells (LGCs). Gain-of-function assay was further performed by overexpression of mitochondrial transcription factor A (TFAM, a downstream target of NRF1 gene (Piantadosi \& Suliman 2006)) in NRF1 knockdown goat LGCs. The results indicate that NRF1 plays a critical role in regulating goat LGC steroidogenesis and apoptosis, which is of great significance to understand the role of NRF1 in follicular development and atresia.

\section{Materials and methods}

\section{Cell culture}

Goat GCs were isolated from healthy follicles $(2-5 \mathrm{~mm})$, and cell survival rate was measured by the trypan blue exclusion test $(81.6 \pm 5.9 \%)$. GCs were plated on T-25 culture flasks at $5 \times 10^{4}$ cells $/ \mathrm{cm}^{2}$ with cell culture medium (DMEM/F12 with $10 \%$ fetal bovine serum, 2-mM L-glutamine, $100 \mathrm{IU} / \mathrm{mL}$ of penicillin and $100 \mu \mathrm{g} / \mathrm{mL}$ of streptomycin), and incubated under a humidified atmosphere containing $5 \% \mathrm{CO}_{2}$ at $37^{\circ} \mathrm{C}$. Non-adherent cells were gently removed after 2 days by changing medium. Even if the cells collected were GCs, after $48 \mathrm{~h}$ of culture with serum, the cells probably became LGCs (Tosca et al. 2010). Unless otherwise indicated, all chemicals used in this study were purchased from Sigma-Aldrich Company and the media from Life Technologies. This study was approved by the Animal Ethical Committee of Nanjing Agricultural University.

\section{Cell transfection and infection}

The sequence of NRF1, TFAM and pEX-4 vector was provided in Supplementary data 1 (see section on Supplementary data given at the end of this article). The efficiency of the constructed vectors used in this study was provided in Supplementary Fig. 1. For NRF1 overexpression, goat LGCs were transfected with pEX-4-NRF1 vector (provided by GenePharma, Shanghai, China, pEX-4-NRF1 group) or pEX-4 empty vector (pEX-4control group) using Lipofectamine 2000 (Life Technologies). For RNA interference experiments, lentiviral supernatants were produced by co-transfection of psPAX2 and pMD2.G with shRNA-3-NRF1 (details were provided in Supplementary Fig. 1 and Supplementary Table 1, shNRF1 group) or scramble shRNA vector (negative control) into 293T cells. Then goat LGCs were infected with lentivirus in the presence of $8 \mu \mathrm{g} / \mathrm{mL}$ Polybrene for $24 \mathrm{~h}$. To perform gain-of-function assay, NRF1 silenced LGCs were transfected with pEX-4-TFAM vector (provided by GenePharma, Shanghai, China, shNRF1+pEX-4-TFAM group) using Lipofectamine 2000. NRF1-knockdown LGCs were transfected with pEX-4 used as control (shNRF1+pEX4-control group). The transfected and infected LGCs were cultured for another $48 \mathrm{~h}$ before analysis.

\section{Steroid assay}

The concentrations of $\mathrm{P}_{4}$ and $\mathrm{E}_{2}$ in culture medium were measured by radioimmunoassay (RIA) using commercial kits (lodine [ $\left.{ }^{125} \mathrm{I}\right]$-Prog RIA Kit, No. RG5-04; lodine [ $\left.{ }^{125} \mathrm{I}\right]-\mathrm{E}_{2}$ RIA Kit, No. RG6-04; Jiuding Biotechniques, Tianjin, China). Before analysis, each sample was 2-, 10-, 25- and 50-fold diluted with Dulbecco's phosphate-buffered saline (DPBS) and $100 \mu \mathrm{L}$ of the diluted fluid was analyzed. The sensitivity of the assays for $\mathrm{P}_{4}$ and $\mathrm{E}_{2}$ was $0.03 \mathrm{ng} / \mathrm{mL}$ and $2.1 \mathrm{pg} / \mathrm{mL}$ respectively. The intra- and inter-assay coefficients of variation for $P_{4}$ and $E_{2}$ were $7.2 \%$ and $8.9 \%$, and $7.7 \%$ and $8.9 \%$ respectively.

\section{Assessment of ATP levels, ATPase and CCO enzyme activity}

ATP levels were measured by a bioluminescence assay employing the luciferase enzyme using the ATP Determination kit (No. A22066, Invitrogen) according to the procedures described previously (Bacsi et al. 2007). Standard curves for quantification were generated using known amounts of an ATP standard. The ATP content of the samples was determined by comparison with a standard curve, and total ATP levels were expressed as normalized luminance in $\mathrm{nmol} / \mathrm{mg}$ protein. The protein concentration was determined by using bicinchoninic acid (BCA) Protein Assay kit (No. P0012S, Beyotime Biotechnology, Nantong, China).

ATPase activity was determined by measuring the formation rate of phosphoric acid from ATP according to the manufacturer's instruction ( $\mathrm{Na}^{+}-\mathrm{K}^{+}$-ATPase assay kit, No. A070-2; $\mathrm{Ca}^{2+}-\mathrm{Mg}^{2+}{ }_{-}$ ATPase assay kit, No. A070-3; Jiancheng, Nanjing, China). ATPase activity was calculated based on the formula of the kit instructions and expressed as $\mu \mathrm{mol} \mathrm{Pi} / \mathrm{h} / \mathrm{mg}$ protein. The protein concentration was determined by using BCA method.

Cytochrome c oxidase (CCO) activity as a biomarker of mitochondrial function was determined by the Cytochrome c Oxidase Assay kit (No. CYTOCOX1, Sigma) according to the manufacturer's instruction. CCO activity was calculated by the changes in the maximal rate of oxidation of reduced cytochrome c (CYCS) in absorbance at $550 \mathrm{~nm}$, and expressed as $\mu \mathrm{mol} / \mathrm{min} / \mathrm{mg}$ protein. The protein content was quantified by Bradford Protein Assay kit (No. P0006, Beyotime Biotechnology).

\section{Measurement of 8-OHdG level and antioxidant enzyme activities}

Cells were homogenized in lysis buffer and centrifuged at $12,000 \mathrm{~g}$ for $15 \mathrm{~min}$ at $4^{\circ} \mathrm{C}$. The supernatant was immediately collected and used for the measurement of oxidative stress parameters. The concentration of 8-hydroxy-2'deoxyguanosine (8-OHdG) was measured by an 8-hydroxy2'-deoxyguanosine ELISA kit (No. K4160-100, BioVision) 
Table 1 Details of primer sequences, expected product sizes and GenBank accession numbers of genes used for qPCR.

\begin{tabular}{|c|c|c|c|}
\hline Target gene & Primer sequence $\left(5^{\prime}-3^{\prime}\right)$ & Product size $(b p)$ & Accession number \\
\hline \multirow[t]{2}{*}{ NRF1 } & F: 5'-AGGCTGGGGCAAAGAAAG-3' & 303 & AY368269.1 \\
\hline & R: 5'-CCAACCTGGATAAGCGAGAC-3' & & \\
\hline \multirow[t]{2}{*}{ STAR } & F: 5'-GGTCCCCGAGACTTTGTGAG-3' & 262 & XM_013975437.1 \\
\hline & R: 5'-AATCCACTTGGGTCTGCGAG-3' & & \\
\hline \multirow[t]{2}{*}{$3 B H S D$} & F: 5'-AGACCAGAAGTTCGGGAGGAA-3' & 292 & NM_001285716.1 \\
\hline & R: 5'-TCTCCСTGTAGGAGTTGGGC-3' & & \\
\hline \multirow[t]{2}{*}{ CYP19A1 } & F: 5'-CAGCATGGTGTCCGAAGTTG-3' & 133 & NM_001285747.1 \\
\hline & R: 5'-GGGCCCAATTCCCAGAAAGT-3' & & \\
\hline \multirow[t]{2}{*}{ TFAM } & F: 5'-CCAAGCTGTGGAGGGAACTT-3' & 229 & XM_005699371 \\
\hline & R: 5'-GCTGACCGAGGTCTTTTTGG-3' & & \\
\hline \multirow[t]{2}{*}{ SOD2 } & F: 5'-GTGAACAACCTCAACGTCGC-3' & 300 & XM_013966636 \\
\hline & R: 5'-GCGTCCCTGCTCCTTATTGA-3' & & \\
\hline \multirow[t]{2}{*}{ CAT } & F: 5'-CACTCAGGTGCGGGATTTCT-3' & 159 & GQ204786.1 \\
\hline & R: 5'-ATGCGGGAGCCATATTCAGG-3' & & \\
\hline \multirow[t]{2}{*}{ GPX1 } & F: 5'-ACATTGAAACCСТGCTGTCC-3' & 216 & XM_005695962.2 \\
\hline & R: 5'-TCATGAGGAGCTGTGGTCTG-3' & & \\
\hline \multirow[t]{2}{*}{$B A X$} & F: 5'-GCATCCACCAAGAAGCTGAG-3' & 130 & XM_002701934 \\
\hline & R: 5'-CCGCCACTCGGAAAAAGAC-3' & & \\
\hline \multirow[t]{2}{*}{$B C L 2$} & F: 5'-ATGTGTGTGGAGAGCGTCA-3' & 182 & NM_001166486.1 \\
\hline & R: 5'-AGAGACAGCCAGGAGAAATC-3' & & \\
\hline \multirow[t]{2}{*}{ CASP3 } & F: 5'-GCTCGAGCTCATGCACATTC-3' & 197 & NM_001286089.1 \\
\hline & R: 5'-CCATTGGGCACTTGGCATAC-3' & & \\
\hline \multirow[t]{2}{*}{ CASP9 } & F: 5'-AGTCAGGCCCTTCCTTTGTT-3' & 193 & XM_005690814 \\
\hline & R: 5'-ATGGGTCCTGCTTCATCACT-3' & & \\
\hline \multirow[t]{2}{*}{ GAPDH } & F: 5'-CGACTTCAACAGCGACACTCAC-3' & 119 & NM_001034034.1 \\
\hline & R: 5'-CCCTGTTGCTGTAGCCGAATTC-3' & & \\
\hline
\end{tabular}

3BHSD, 3 beta-hydroxysteroid dehydrogenase/isomerase; $B A X, B C L 2$ associated $\mathrm{X}$, apoptosis regulator; $B C L 2, \mathrm{BCL}$, apoptosis regulator; CASP3, caspase 3; CASP9, caspase 9; CAT, catalase; CYP19A1, cytochrome P450 family 19 subfamily A member 1; GAPDH, glyceraldehyde-3phosphate dehydrogenase; GPX1, glutathione peroxidase 1; NRF1, nuclear respiratory factor 1; STAR, steroidogenic acute regulatory protein, mitochondrial; SOD2, superoxide dismutase 2; TFAM, transcription factor A, mitochondrial.

using a standard protocol in the manual described previously (Chiang et al. 2013). The concentration of 8-OHdG was calculated by comparison with predetermined $8-\mathrm{OHdG}$ standard curve, and expressed as $\mu \mathrm{mol} \mathrm{Pi} / \mathrm{h} / \mathrm{mg}$ protein. The protein concentration was determined by using BCA method. The sensitivity of $8-\mathrm{OHdG}$ was $0.94 \mathrm{ng} / \mathrm{mL}$, and the coefficients of variation for intra- and inter-assay were $5.5 \%$ and $6.1 \%$ respectively.

Enzyme activities of superoxide dismutase (SOD) were detected using the SOD Assay Kit (No. S311-10, Dojindo Molecular Technologies, Tokyo, Japan) as described previously (Grasselli et al. 2010). Catalase (CAT), glutathione peroxidase (GPx), intracellular reduced glutathione $(\mathrm{GSH})$ and oxidized glutathione (GSSG) were determined by using commercially available assay kits from Beyotime
Biotechnology (Catalase Assay Kit, No. S0051; Cellular Glutathione Peroxidase Assay kit, No. S0056; GSH and GSSG Assay Kit, No. S0053; Nantong, China) by strictly following the manufacturer's instruction. The antioxidant enzyme activities were expressed as $U / \mathrm{mg}$ of protein, and the levels of GSH and GSSG were expressed as $\mathrm{nmol} / \mathrm{mg}$ protein. The protein concentration was determined by using BCA method.

\section{mtDNA copy number quantification}

Mitochondrial DNA (mtDNA) copy number quantification was performed by quantitative real-time reverse transcription polymerase chain reaction (qPCR) as previously described (Zhang et al. 2016).

Table 2 Details of antibodies used for Western blot in this study.

\begin{tabular}{lll}
\hline Antibodies & Cat No. & Source \\
\hline STAR & SC-25806 & Santa Cruz \\
3BHSD & NB110-78644 & Novus $(\mathrm{CO}$, USA) \\
CYP19A1 & ab18995 & Abcam \\
BAX & SC-526 & Santa Cruz \\
BCL2 & BA0412 & Boster (Wuhan, China) \\
CYCS & ab16076 & Abcam \\
ACTB & AA128 & Beyotime (Haimen, China) \\
\hline
\end{tabular}

3BHSD, 3 beta-hydroxysteroid dehydrogenase/isomerase; ACTB, actin beta; BAX, BCL2 associated X, apoptosis regulator; BCL2, BCL2, apoptosis regulator; CYCS, cytochrome C, somatic; CYP19A1, cytochrome P450 family 19 subfamily A member 1; STAR, steroidogenic acute regulatory protein. 

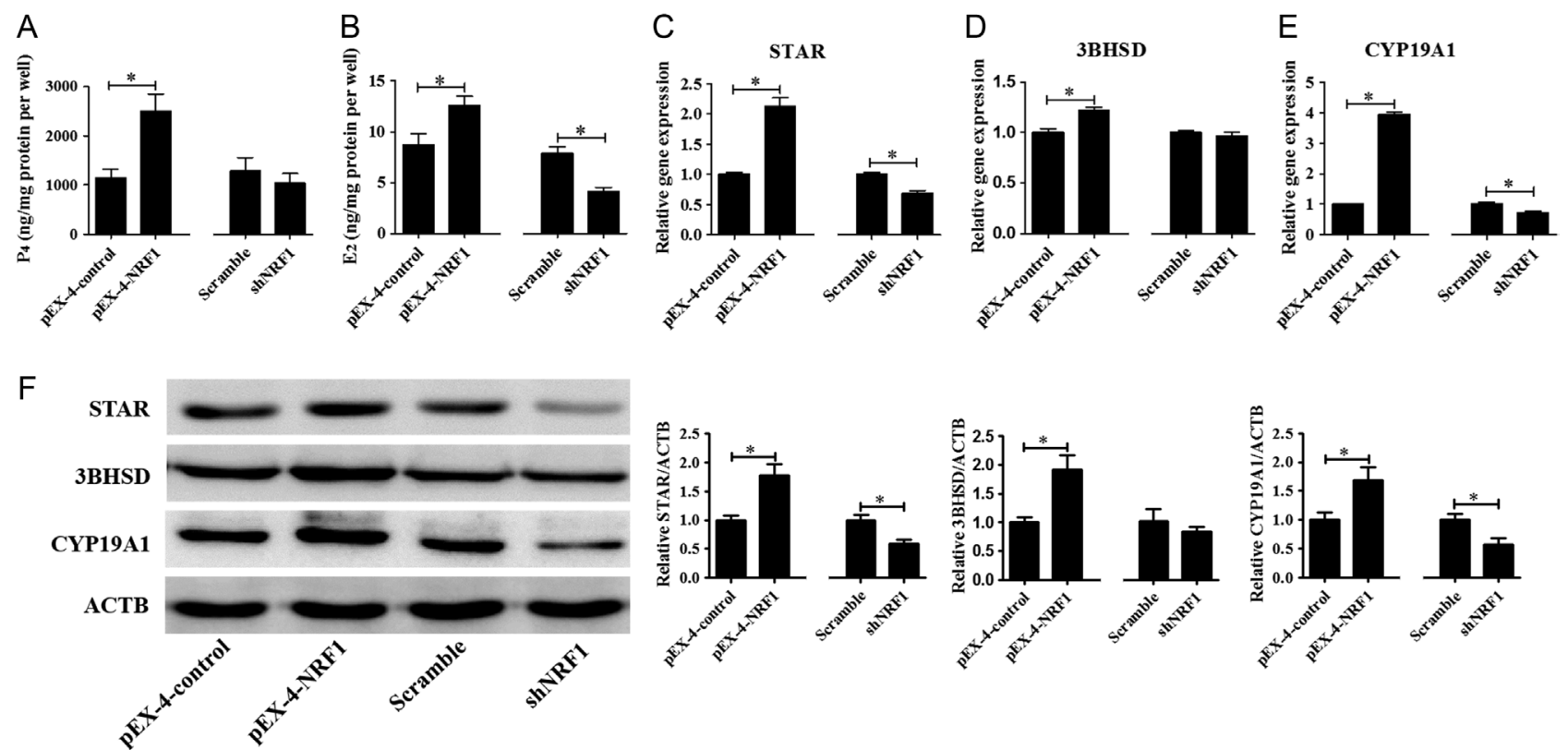

Figure 1 NRF1 regulates $\mathrm{P}_{4}$ and $\mathrm{E}_{2}$ synthesis in goat LGCs. (A and B) Concentrations of progesterone $\left(\mathrm{P}_{4}\right)$ and estradiol $\left(\mathrm{E}_{2}\right)$ in NRF1 overexpressed or silenced LGCs culture medium were detected by RIA. (C, D and E) The mRNA levels of genes (STAR, 3BHSD and CYP19A1) associated with steroid hormone synthesis in NRF1 overexpressed or suppressed LGCs were analyzed by qPCR. The relative expression levels were normalized to the expression amount of GAPDH. (F) Protein levels of STAR, 3BHSD and CYP19A1 in NRF1 overexpressed or silenced LGCs were immunoblotted and quantified. ACTB served as an internal control. Data are expressed as mean \pm S.E.M. (Student's $t$-test, $n=4$ ), $* P<0.05$.

\section{Gene expression analysis}

Total RNA was extracted using a commercial RNA isolation kit (No. 74104, Qiagen) and reverse-transcribed into cDNA using a PrimeScript RT reagent kit with gDNA Eraser (No. RR047A, Takara) according to the manufacturer's instructions. qPCR was performed on a Step One Plus Real-Time PCR System (Applied BioSystems) using FastStart Universal SYBR Green Master kit (No. 04913850001, Roche). Primer sequences were provided in Table 1. Melting curves were analyzed to verify amplification specificity. Gene expression levels were quantified using the form of $2^{-\triangle \Delta \mathrm{Ct}}$ and normalized to GAPDH mRNA expression.

\section{Cell apoptosis analysis}

Cell apoptosis was analyzed using the Annexin V-APC and 7-ADD apoptosis detection kit (No. KGA1025, KeyGEN,
Nanjing, China) according to the manufacturer's instructions. Briefly, the cells about 90\% confluency were detached and resuspended in DPBS, then incubated with $5 \mu \mathrm{L}$ of APClabeled Annexin $\mathrm{V}$ for $5 \mathrm{~min}$, followed by an additional $5 \mu \mathrm{L}$ of 7-ADD for $15 \mathrm{~min}$ in darkness. The fluorescence of the cells was determined by a flow cytometer (BD Biosciences, NJ, USA).

\section{Caspase activity}

Caspase 3 (CASP3) and caspase 9 (CASP9) activities were determined by using commercially available assay kits from Beyotime Biotechnology (Caspase 3 Activity Assay Kit, No. C1116; Caspase 9 Activity Assay Kit, No. C1158) by following the manufacturer's instruction. The CASP3 and CASP9 enzyme activities
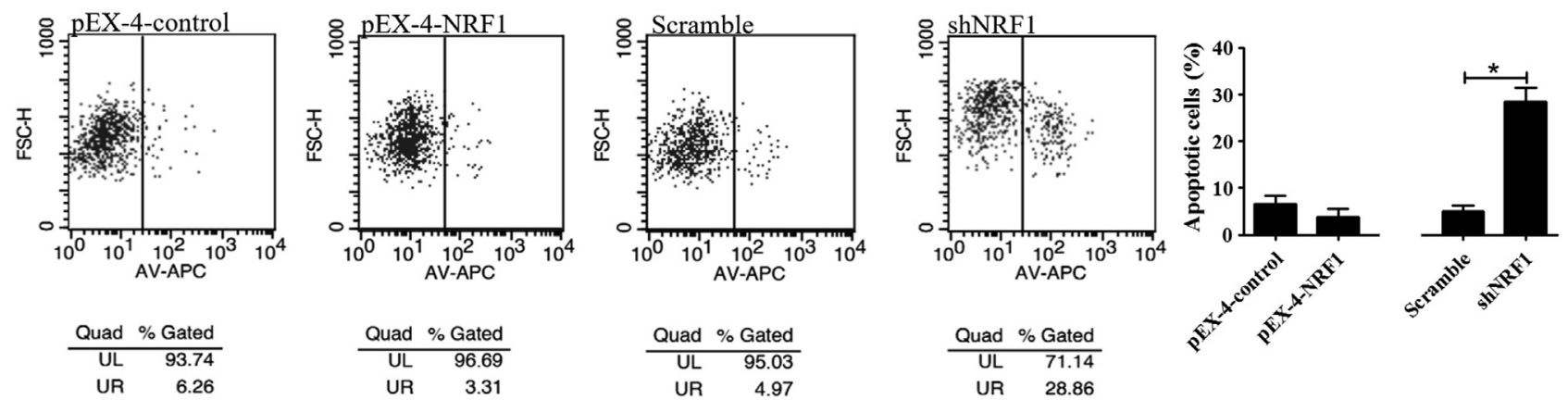

Figure 2 NRF1 silence induces goat LGC apoptosis. The percentage of apoptotic cells was analyzed by flow-cytometry using Annexin V-APC/7AAD staining in NRF1 overexpressed or suppressed LGCs. Quadrants: Left, live cells; Right, apoptotic cells. Data are expressed as mean \pm S.E.M. (Student's $t$-test), $* P<0.05$. 
A

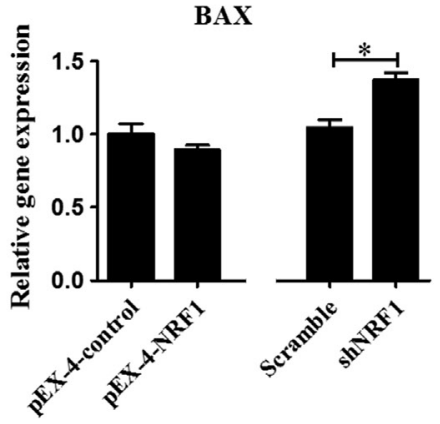

$\mathrm{B}$

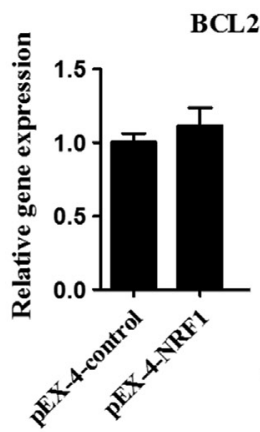

BCL2

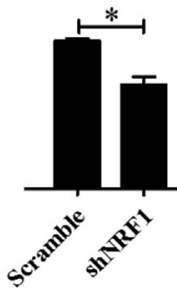

C

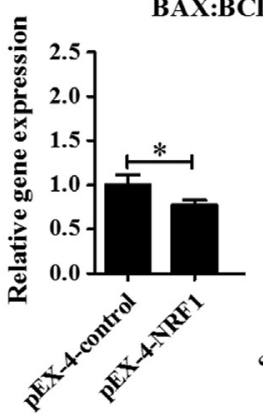

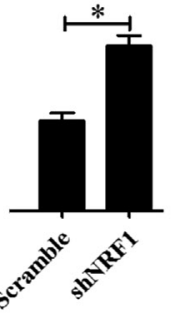
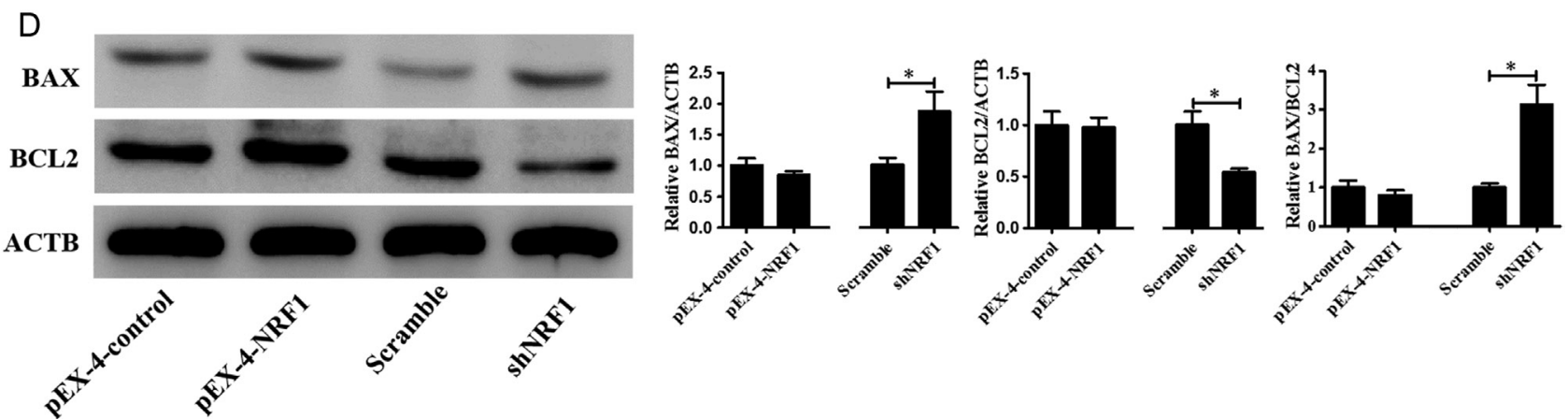

Figure 3 Effects of NRF1 on apoptosis-related genes BAX and BCL2 expression in goat LGCs. (A, B and C) Relative expression levels of $B A X$ and $B C L 2$, and the ratio of BAX/BCL2 in NRF1 overexpressed or silenced LGCs were analyzed by qPCR. The relative expression levels were normalized to the expression amount of GAPDH. (D) BAX and BCL2 protein levels in NRF1 overexpressed or silenced LGCs were immunoblotted and quantified. ACTB served as an internal control. Data are expressed as mean \pm S.E.M. (Student's $t$-test, $n=4), * P<0.05$.

were calculated with reference to a standard curve, and the data were represented as $\mathrm{U} / \mathrm{mg}$ of protein. The protein content was determined with Bradford method.

\section{Mitochondrial and cytosolic fractionation}

LGC fractionation (mitochondria and cytosol) protein extracts obtained from different treatment conditions were subjected to Western blot for CYCS protein analysis. The Cell Mitochondria
A
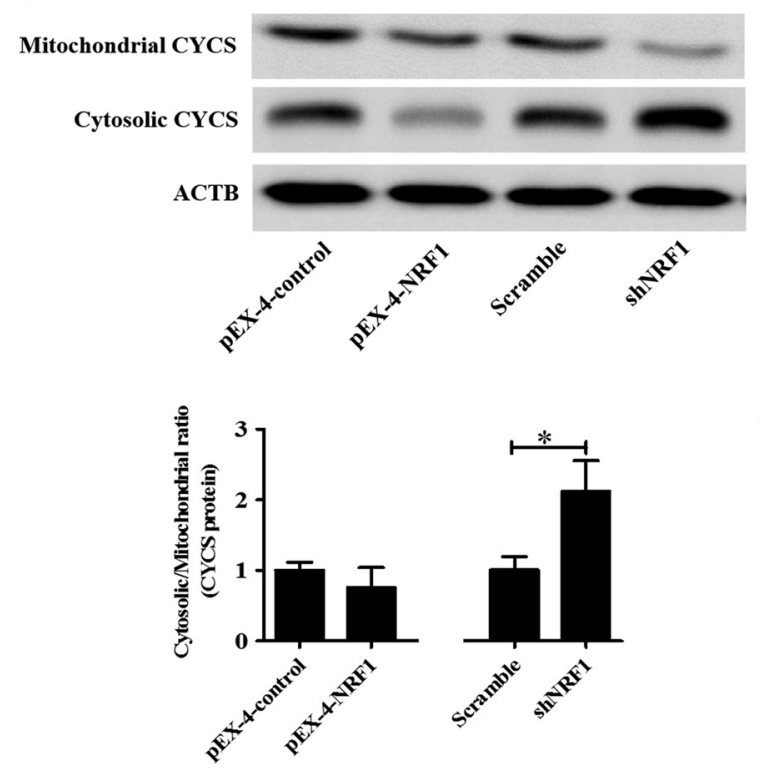

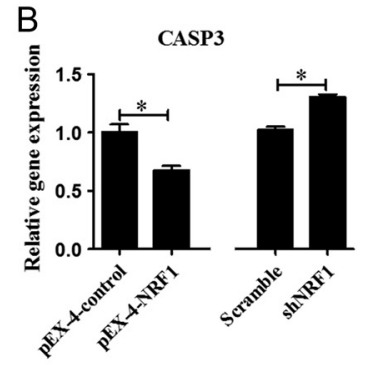

C

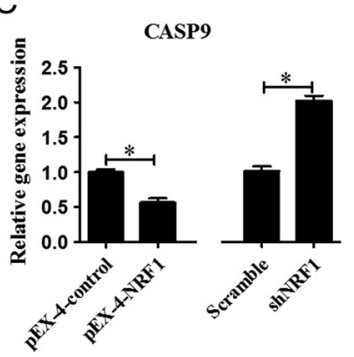

Figure 4 Effects of NRF1 on CYCS release, CASP3 and CASP9 expression in goat LGCs. (A) Western blotting analysis for detecting the CYCS distribution and quantification in mitochondria and cytosol of NRF1 overexpressed or silenced LGCs. ACTB served as an internal control. (B and C) The expression of apoptosis-related genes CASP3 and CASP9 in NRF1 overexpressed or silenced LGCs was analyzed by qPCR. The relative expression levels were normalized to the expression amount of GAPDH. Data are expressed as mean \pm S.E.M. (Student's $t$-test, $n=4), * P<0.05$. 
Table 3 Effects of NRF1 on caspase activity in goat LGCs.

\begin{tabular}{lcc}
\hline Group & CASP3 $(\mathrm{U} / \mathrm{mg}$ pro $)$ & CASP9 $(\mathrm{U} / \mathrm{mg}$ pro $)$ \\
\hline pEX-4-control & $582.4 \pm 49.1^{\mathrm{a}}$ & $273.9 \pm 17.3^{\mathrm{a}}$ \\
pEX-4-NRF1 & $397.1 \pm 19.3^{\mathrm{b}}$ & $198.4 \pm 11.9^{\mathrm{b}}$ \\
Scramble & $543.7 \pm 27.6$ & $295.1 \pm 16.4$ \\
shNRF1 & $729.8 \pm 34.6^{*}$ & $329.7 \pm 13.8^{*}$ \\
\hline
\end{tabular}

Data are presented as mean \pm S.E.M. (Student's $t$-test, $n=4$ ).

In the same parameter, ${ }^{a, b}$ values mean significant difference between pEX-4-NRF1 (NRF1 overexpression) and pEX-4-control groups

$(P<0.05)$; *values mean significant difference between shNRF1

(NRF1 silence) and scramble groups $(P<0.05)$.

CASP3, caspase 3; CASP9, caspase 9; pro, protein.

Isolation kit (No. C3601, Beyotime Biotechnology) was used to perform mitochondria and cytosol isolation following the manufacturer's protocol.

\section{Western blot analysis}

Total protein was extracted from the cells with radio immunoprecipitation (RIPA) lysis buffer (No. P0013B, Beyotime Biotechnology) and quantified by BCA method. Protein samples $(30 \mu \mathrm{g})$ were diluted in gel-loading buffer, boiled for $10 \mathrm{~min}$, separated in an $8-12 \%$ sodium dodecyl sulfate polyacrylamide gel electrophoresis (SDS-PAGE) and then electro-transferred onto a polyvinylidene fluoride (PVDF) membrane (Millipore). The membrane was blocked with $5 \%(\mathrm{w} / \mathrm{v})$ bovine serum albumin for $1 \mathrm{~h}$ at room temperature (RT), followed by incubation with a primary antibody overnight at $4{ }^{\circ} \mathrm{C}$. Details of the primary antibodies were provided in Table 2. After washing, the proteins of interest were incubated with secondary antibodies (No. A0216 for CYCS protein, 1:1000 dilution; No. A0208 for other target proteins, 1:1000 dilution; Beyotime Biotechnology) at RT for $1 \mathrm{~h}$. After washing, the immunoreactive bands were visualized using Image Quant LAS 4000 (Fujifilm, Tokyo, Japan) with the Western Bright ECL kit (No. K-12045-D20, Advansta, CA, USA). Band intensities were estimated by densitometry and
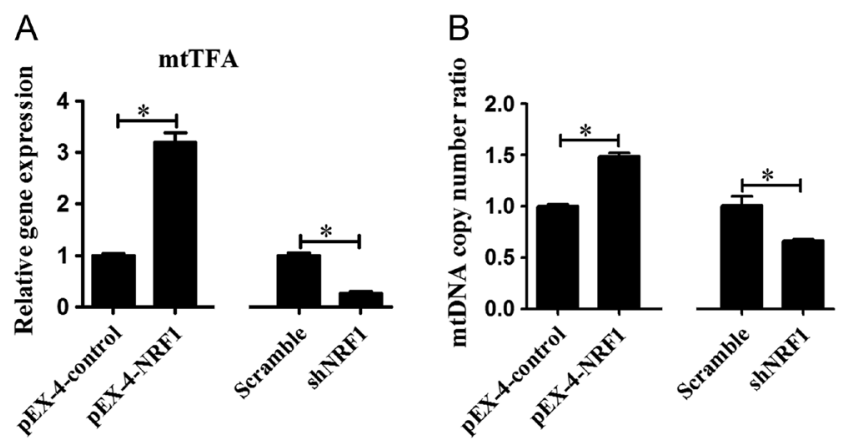

Figure 5 NRF1 silence is involved in mitochondrial dysfunction in goat LGCs. (A) qPCR was used to detect mRNA level of TFAM in NRF1 overexpressed or silenced LGCs. The relative expression levels were normalized to the expression amount of GAPDH. (B) The mtDNA copy number in NRF1 overexpressed or silenced LGCs was determined by qPCR. The ratio of mtDNA to nuclear DNA reflects the relative mtDNA copy number. Data are expressed as mean \pm S.E.M. (Student's $t$-test, $n=4), * P<0.05$. normalized to actin beta (ACTB). Bands were quantified using Image J software (Wayne Rasband, Maryland, USA).

\section{Statistical analysis}

All data were analyzed with statistical product and service solutions (SPSS, version 19.0) (IBM, Chicago, IL, USA), presented as mean values \pm standard error of the mean (S.E.M.), and calculated from at least three independent experiments $(n>3)$. Student's $t$-test was performed to calculate $P$ value, where $P<0.05$ was considered a statistically significant difference.

\section{Results}

\section{NRF1 promotes $P_{4}$ and $E_{2}$ synthesis in goat LGCS}

To characterize NRF1 in steroidogenesis of goat LGCs in vitro, we first examined its effect on $P_{4}$ and $E_{2}$ production. The concentrations of $\mathrm{P}_{4}$ and $\mathrm{E}_{2}$ were significantly increased with the overexpression of NRF1 $(P<0.05$, Fig. $1 \mathrm{~A}$ and $\mathrm{B})$, while the level of $\mathrm{E}_{2}$ was significantly decreased by NRF1 silencing $(P<0.05$, Fig. 1B). The expression levels of steroidogenic acute regulatory protein $(S T A R), 3$ beta-hydroxysteroid dehydrogenase/isomerase (3BHSD) and cytochrome P450 family 19 subfamily A member 1 (CYP19A1) crucial genes of steroidogenesis - were significantly increased with the overexpression of NRF1 $(P<0.05$, Fig. 1C, D, E and F). Accordingly, knockdown of NRF1 in LGCs significantly decreased the expression levels of STAR and CYP19A1 ( $P<0.05$, Fig. 1C, D, E and F). These results support the assumption that NRF1 may be critical for goat LGC steroidogenesis.

\section{Suppression of NRF1 induces goat LGC apoptosis}

To investigate whether NRF1 plays a role in goat LGC apoptosis, Annexin V-APC and 7-ADD staining were used to examine the effects of NFR-1 overexpression or suppression on LGC apoptosis. The results showed that NRF1 silencing significantly increased the percentage of cell apoptosis $(28.92 \% \pm 3.16 \%)$ compared with scramble group $(5.15 \% \pm 1.82 \%, P<0.05$, Fig. 2$)$. qPCR and Western blot assays also confirmed the enhanced expression of BCL2 associated X (BAX) and reduced BCL2 level in NRF1 suppressed LGCs, which was supported by the increased ratio of BAX/BCL2 $(P<0.05$, Fig. 3A, $\mathrm{B}, \mathrm{C}$ and $\mathrm{D})$. In contrast, the overexpression of NRF1 significantly decreased the ratio of BAX/BCL2 in LGCs $(P<0.05$, Fig. 3C). These data suggest reduced expression of NRF1 might contribute to the apoptosis of goat LGCs.

Furthermore, we observed a significant release of CYCS from mitochondria to cytosol with NRF1 suppression $(P<0.05$, Fig. 4A). Concomitantly, the mRNA levels of CASP3 and CASP9 were significantly increased in NRF1 suppressed LGCs $(P<0.05$, Fig. 4B and $\mathrm{C})$, with enhanced cleavage activity $(P<0.05$, 
Table 4 Effects of NRF1 on ATP and CCO content, and ATPase activity in goat LGCs.

\begin{tabular}{lcccc}
\hline Group & ATP $(\mathrm{nmol} / \mathrm{mg}$ pro $)$ & $\mathbf{C C O}(\mu \mathrm{mol} / \mathrm{min} / \mathrm{mg}$ pro $)$ & $\mathbf{N a}^{+}-\mathbf{K}^{+}-\mathbf{A T P a s e}(\mu \mathrm{mol} \mathbf{P i} / \mathrm{h} / \mathrm{mg}$ pro $)$ & $\mathbf{C a}^{2+}-\mathbf{M g}^{2+}-\mathbf{A T P a s e}(\mu \mathrm{mol} \mathbf{P i} / \mathbf{h} / \mathrm{mg} \mathbf{p r o})$ \\
\hline pEX-4-control & $28.43 \pm 3.25^{\mathrm{a}}$ & $2.09 \pm 0.46^{\mathrm{a}}$ & $68.27 \pm 1.83^{\mathrm{a}}$ & $15.41 \pm 2.06^{\mathrm{a}}$ \\
pEX-4-NRF1 & $37.61 \pm 2.38^{\mathrm{b}}$ & $4.23 \pm 0.28^{\mathrm{b}}$ & $92.4 \pm 2.36^{\mathrm{b}}$ & $21.29 \pm 1.47^{\mathrm{b}}$ \\
Scramble & $25.72 \pm 1.98$ & $2.18 \pm 0.32$ & $61.5 \pm 2.43$ & $16.03 \pm 1.28$ \\
shNRF1 & $18.29 \pm 2.64^{*}$ & $1.61 \pm 0.25^{*}$ & $41.25 \pm 1.84^{*}$ & $12.47 \pm 1.82$ \\
\hline
\end{tabular}

All values are mean \pm S.E.M. (Student's $t$-test, $n=4$ ).

In the same parameter, ${ }^{a}, \mathrm{~b} V a l u e s$ mean significant difference between $\mathrm{pEX}-4-\mathrm{NRF} 1$ (NRF1 overexpression) and pEX-4-control groups $(P<0.05)$;

*values mean significant difference between shNRF1 (NRF1 silence) and Scramble groups $(P<0.05)$.

ATP, adenosine triphosphate; CCO, cytochrome c oxidase; pro, protein.

Table 3). However, the expression (mRNA and cleavage activity) of CASP3 and CASP9 was significantly decreased by the overexpression of NRF1 $(P<0.05$, Fig. $4 \mathrm{~B}$ and $\mathrm{C}$, and Table 3). These data suggest NRF1 silencing impairs cell survival probably though mitochondria-mediated apoptosis pathway.

\section{NRF1 regulates mitochondrial function in goat LGCs}

To investigate the mechanism how NRF1 regulates steroidogenesis and cell survival, we aim to identify the responsible downstream targets of NRF1 in goat LGCs. It has been reported that NRF1 functions as a major transcription factor that activates mitochondrial function. The effects of NRF1 on mitochondrial biogenesis, energy metabolism and redox states were investigated. By using $\mathrm{qPCR}$, we found that mitochondrial biogenesis marker TFAM and mtDNA copy number were significantly decreased by the knockdown of NRF1, while their levels were significantly increased by the overexpression of NRF1 $(P<0.05$, Fig. 5). In addition, the overexpression of NRF1 in LGCs significantly increased the ATP and CCO levels, and enhanced the activities of $\mathrm{Na}^{+}-\mathrm{K}^{+}$-ATPase and $\mathrm{Ca}^{2+}-\mathrm{Mg}^{2+}$-ATPase $(P<0.05$, Table 4). On the contrary, the ATP and CCO levels, and the activity of $\mathrm{Na}^{+}-\mathrm{K}^{+}$-ATPase were significantly reduced with NRF1 silencing in goat LGCs $(P<0.05$, Table 4$)$.

The redox state assay was performed by evaluating the 8-OHdG level, the activities of antioxidant enzymes SOD, CAT and GPx, as well as the ratio of GSH/GSSG. As shown in Table 5, silencing of NRF1 in goat LGCs significantly increased 8-OHdG level $(P<0.05)$. The mRNA levels and activities of SOD, GPx and CAT were both significantly reduced by the silencing of NRF1 $(P<0.05$, Fig. 6 and Table 5). In contrast, the activities of SOD, CAT, GPx and GSH were significantly upregulated in NRF1 overexpressed LGCs, followed by the increased ratio of GSH/GSSG $(P<0.05$, Table 5$)$. Accordingly, the mRNA levels of superoxide dismutase 2 (SOD2) and CAT were significantly elevated with NRF1 overexpression $(P<0.05$, Fig. 6). Surprisingly, GSSG levels were not significantly affected by NRF1 overexpression or silencing (Table 5). These data indicate that NRF1 plays an important role in mitochondrial function, suggesting NRF1 regulates steroidogenesis and cell survival probably through the regulation of mitochondria.

\section{NRF1 regulates steroidogenesis and cell survival by targeting TFAM in goat LGCS}

We further identified the downstream target genes of NRF1 in LGC regulation. It has been reported that the activation of proximal TFAM promoter is highly dependent on NRF1 and decreased TFAM represses mitochondrial function (Choi et al. 2004). By using gain-of-function assay, the results showed that the gain of TFAM compensated the abnormal $\mathrm{E}_{2}$ expression, and recovered the decreased expression of STAR, 3BHSD and CYP19A1 in NRF1 silenced LGCs $(P<0.05$, Fig. 7A, B and E). In addition, the overexpression of TFAM could significantly reduce the percentage of cell apoptosis and decrease the expression ratio of BAX to BCL2 in NRF1 suppressed LGCs, along with the increased expression of CASP9 $(P<0.05$, Fig. 7 C, D and $\mathrm{E}$, and Table 6). The disturbed mitochondrial function and the redox balance in NRF1 knockdown LGCs could

Table 5 Effects of NRF1 on oxidative stress in goat LGCs.

\begin{tabular}{|c|c|c|c|c|c|c|c|}
\hline Group & $\begin{array}{c}\text { 8-OHdG } \\
(\mu \mathrm{mol} \text { Pi/h/mg pro })\end{array}$ & $\begin{array}{c}\text { SOD } \\
\text { (U/mg pro) }\end{array}$ & $\begin{array}{c}\text { CAT } \\
\text { (U/mg pro) }\end{array}$ & $\begin{array}{c}\text { GPx } \\
\text { (U/mg pro) }\end{array}$ & $\begin{array}{c}\text { GSH } \\
\text { (nmol/mg pro) }\end{array}$ & $\begin{array}{c}\text { GSSG } \\
\text { (nmol/mg pro) }\end{array}$ & GSH/GSSG \\
\hline pEX-4-control & $1.18 \pm 0.13$ & $11.84 \pm$ & 6.49 & $30.26 \pm 5.41^{\mathrm{a}}$ & $17.47 \pm 2.16^{\mathrm{a}}$ & $1.03 \pm 0.32$ & $17.36 \pm 2.47^{a}$ \\
\hline pEX-4-NRF1 & $0.89 \pm 0.21$ & $18.76 \pm 1.91^{b}$ & $11.52 \pm 1.74^{\mathrm{b}}$ & $42.63 \pm 3.85^{b}$ & $23.81 \pm 2.35^{b}$ & $0.73=$ & $30.58 \pm 4.83^{b}$ \\
\hline Scramble & $1.21 \pm 0.19$ & $12.35 \pm 2.23$ & $5.81 \pm 0.89$ & $27.58 \pm 2.92$ & $16.15 \pm 1.92$ & $1.19 \pm 0.21$ & $13.64 \pm 1.89$ \\
\hline shNRF1 & $4.17 \pm 0.26^{*}$ & $8.51 \pm 1.46^{*}$ & $3.76 \pm 1.21 *$ & $18.37 \pm 3.26^{*}$ & $11.49 \pm 1.68^{*}$ & $1.37 \pm 0.16$ & $9.06 \pm 2.18^{*}$ \\
\hline
\end{tabular}

Data are presented as mean \pm S.E.M. (Student's $t$-test, $n=4)$.

In the same parameter, ${ }^{a, b}$ Values represent significant difference between pEX-4-NRF1 (NRF1 overexpression) and pEX-4-control groups $(P<0.05)$; *values represent significant difference between shNRF1 (NRF1 silence) and Scramble groups $(P<0.05)$.

8-OHdG, 8-hydroxy-2'-deoxyguanosine; CAT, catalase; GPx, glutathione peroxidase; GSH, reduced glutathione; GSSG, oxidized glutathione; pro, protein; SOD, superoxide dismutase. 

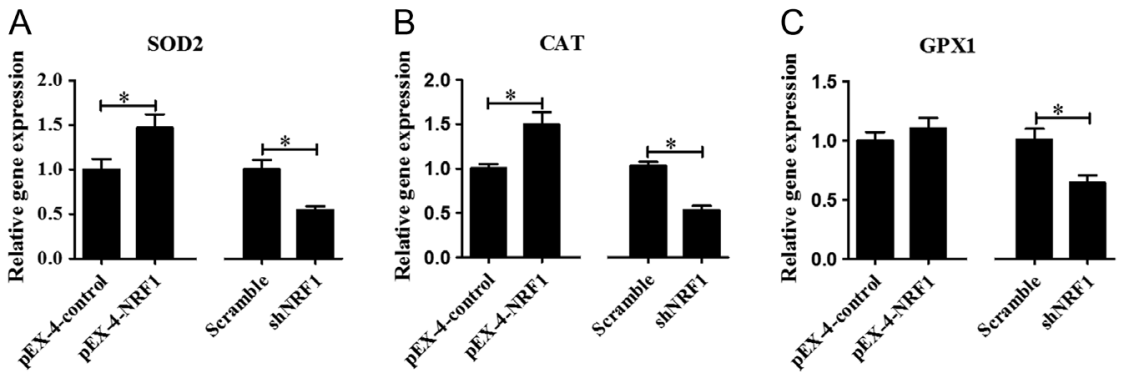

Figure 6 NRF1 regulates oxidative stress in goat LGCs. (A, B and C) Antioxidant related genes SOD2, CAT and GPX1 expression levels in NRF1 overexpressed or silenced LGCs were analyzed by qPCR. The relative expression levels were normalized to the expression amount of GAPDH. Data are expressed as mean \pm S.E.M. (Student's $t$-test, $n=4),{ }^{*} P<0.05$.

be recovered by overexpression of TFAM $(P<0.05$, Fig. 8, Tables 7 and 8). These data further indicate NRF1 regulates steroidogenesis and cell apoptosis by targeting the mitochondrial regulator TFAM.

\section{Discussion}

Here, we identify that NRF1 is required for goat LGC steroidogenesis and cell survival. NRF1 regulates goat LGC identity through mitochondria-dependent pathway, and mitochondrial transcription factor TFAM may participate in this regulation process. These findings underscore the importance of NRF1 regulation in goat LGC steroid synthesis and apoptosis.

STAR participates in the initial and rate-limiting step in steroidogenesis, which mediates the transport of cholesterol from the outer to the inner mitochondrial membrane (Arakane et al. 1998). The cholesterol converted to $\mathrm{P}_{4}$ and $E_{2}$ is catalyzed by the key enzymes of cytochrome P450 family 11 subfamily A member 1 (CYP11A1), 3BHSD and CYP19A1 (Ke et al. 2004, Sahmi et al. 2004). The expression levels of these enzymes could reflect the production of $\mathrm{P}_{4}$ and $\mathrm{E}_{2}$ (Mizutani et al. 2015). In the present study, the overexpression of NRF1 in goat LGCs significantly increased the mRNA and
A

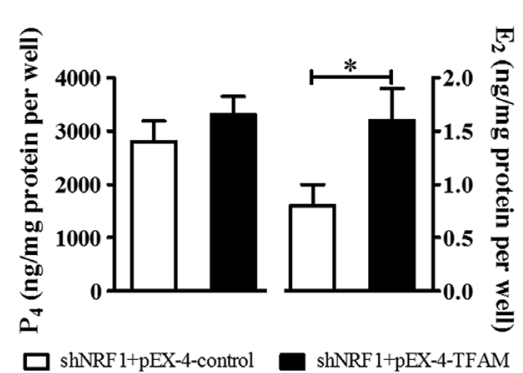

B

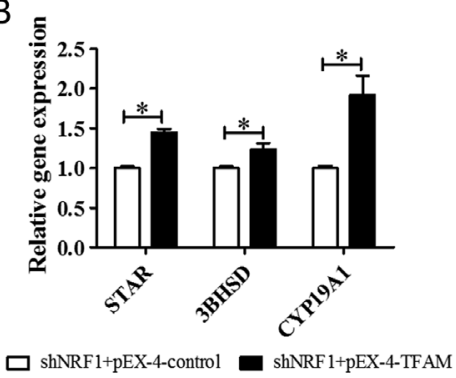

D

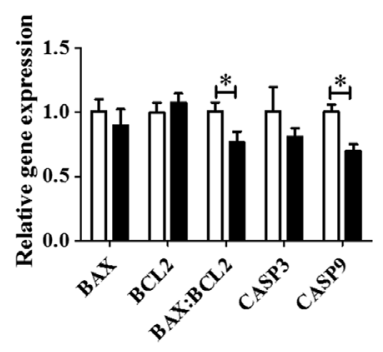

C

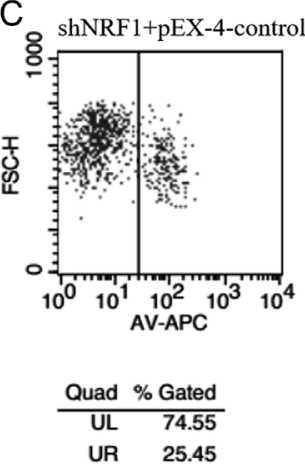

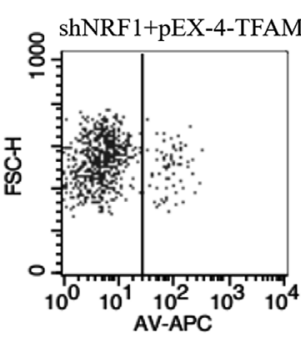

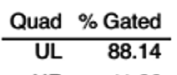

$\mathrm{E}$

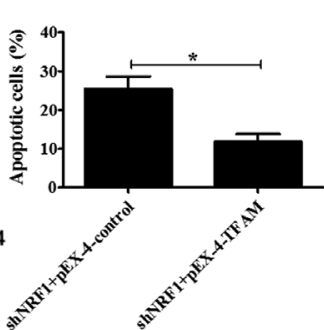

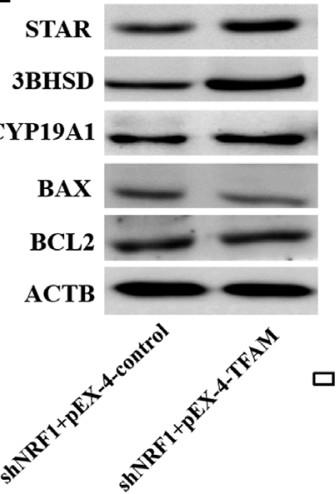

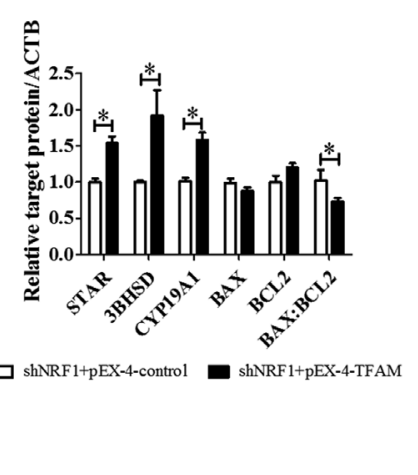

Figure 7 Gain of TFAM rescues steroidogenesis and cell apoptosis in NRF1 silenced goat LGCs. (A and B) Gain of TFAM recovered the $\mathrm{P}_{4}$ and $\mathrm{E}_{2}$ synthesis and steroidogenesis related genes (STAR, 3BHSD and CYP19A1) expression in NRF1 silenced LGCs. The relative expression levels were normalized to the expression amount of GAPDH. (C) Overexpression of TFAM in NRF1 silenced LGCs decreased cell apoptosis percentage. (D) Gain of TFAM rescued the expression of apoptosis-related genes in NRF1 silenced LGCs. The relative expression levels were normalized to the expression amount of GAPDH. (E) The levels of steroidogenesis and cell apoptosis-related proteins were restored by overexpression of TFAM in NRF1 silenced LGCs. ACTB served as an internal control. Data are expressed as mean \pm S.E.M. (Student's $t$-test, $n=4$ ), $* P<0.05$. 
Table 6 Effects of TFAM on caspase activity in NRF1 suppressed goat LGCs.

\begin{tabular}{lcc}
\hline Group & CASP3 (U/mg pro) & CASP9 (U/mg pro) \\
\hline shNRF1 + pEX-4-Control & $691.3 \pm 42.8$ & $342.1 \pm 20.6$ \\
shNRF1 + pEX-4-TFAM & $581.3 \pm 28.1$ & $219.8 \pm 17.6^{*}$ \\
\hline
\end{tabular}

Data are presented as mean \pm S.E.M. (Student's $t$-test, $n=4$ ). In the same parameter, *Values mean significant difference between shNRF1 + pEX-4-TFAM (TFAM overexpression) and shNRF1 + pEX-4control groups $(P<0.05)$.

CASP3, caspase 3; CASP9, caspase 9; pro, protein.

protein levels of STAR, 3BHSD and CYP19A1, as well as the levels of $\mathrm{P}_{4}$ and $\mathrm{E}_{2}$, which was consistent with previous reports (Boruszewska et al. 2013). These results indicate that NRF1 may get involved in the regulation of steroidogenesis in goat LGCs.

It has been reported that mitochondrial dysfunction leads to low levels of testosterone synthesis in Leydig cells (Shabalina et al. 2015). Blocked mitochondrial fusion by mitofusin 2 (Mfn2) knockdown has a negative impact on steroid synthesis (Duarte et al. 2012). Li and coworkers (2016) found that oxidative stress suppressed the activity of STAR and CYP11A1 in mitochondria, and substantially impaired testicular steroidogenesis. In addition, CYCS release was associated with the destruction of mitochondrial structure and steroidogenic function during apoptosis process (Amsterdam et al. 2003). In our study, the silencing of NRF1 significantly decreased the expression levels of STAR, CYP19A1 and $\mathrm{E}_{2}$ production, but increased the release of CYCS. These results were consistent with the previous report that mitochondrial dysfunction impaired steroidogenesis in human cumulus cells in vitro (Ge et al. 2015). These data support that NRF1 regulates the production of steroid hormones through the regulation of mitochondrial function in goat LGCs.

Extensive researches have revealed that the members of BCL2 family play major roles in modulating apoptosis, and the ratio of BAX (proapoptotic protein) to BCL2 (anti-apoptotic protein) is generally regarded as an important indicator of apoptosis (Korsmeyer et al. 1993). Our findings show that the expression level of BAX/BCL2 was significantly increased in NRF1 silenced LGCs. This is consistent with a previous study, which found that NRF1 silence stimulated MCF-7 breast cancer cell apoptosis (Radde et al. 2016). Consequently, the change in mRNA ratio of $\mathrm{BAX} / \mathrm{BCL} 2$ could destabilize mitochondria, lead to CYCS release from mitochondria to cytoplasm and induce caspases activation (Raisova et al. 2001). Caspase activation is regarded as an important step in the execution phase of apoptosis. CASP3 and CASP9 are the most important members of the caspase family. As expected, the release of CYCS, mRNA level and cleavage activity of CASP3 and CASP9 were significantly increased by following NRF1 silencing, which led to mitochondrial dysfunction and cell apoptosis. These results are consistent with the data in the study by Khalaj and coworkers (2013). Our data suggest that lack of NRF1 may lead to goat LGC apoptosis through the mitochondria-dependent apoptotic pathway.

NRF1 participates in the regulation of cellular oxidative damage (Ohtsuji et al. 2008). High levels of 8 -OHdG have been associated with Iow TFAM
A

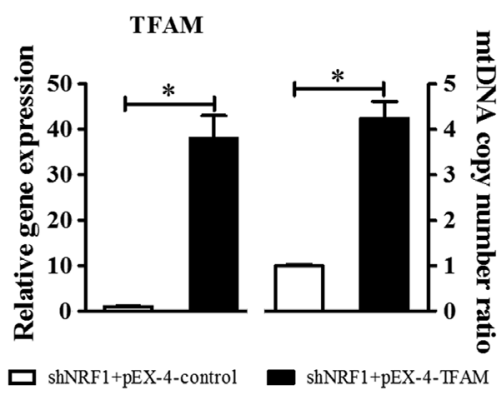

B
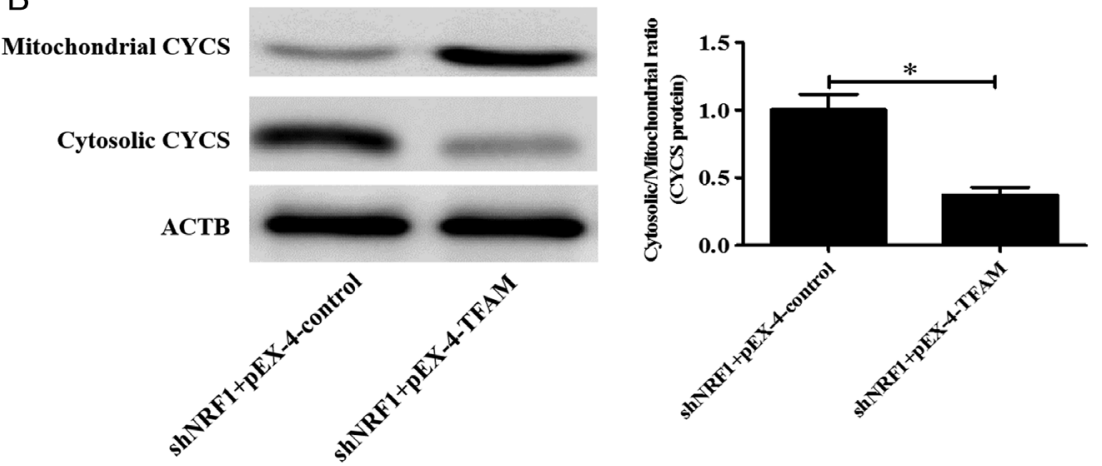

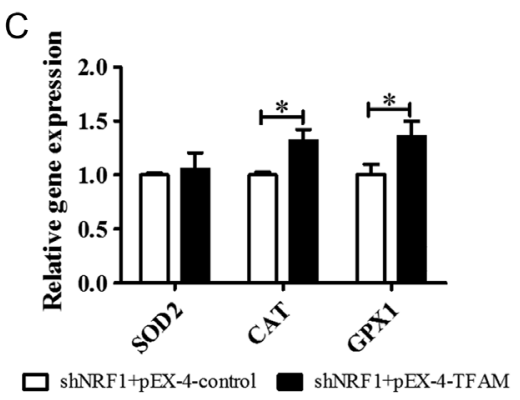

Figure 8 Gain of TFAM restores mitochondrial function in NRF1 silenced LGCs. (A) Overexpression of TFAM restored TFAM expression and mtDNA copy number in NRF1 silenced LGCs. The ratio of mtDNA to nuclear DNA reflects the relative mtDNA copy number. (B) The CYCS distribution in mitochondria and cytosol was recovered by gain of TFAM in NRF1 silenced LGCs. ACTB served as an internal control. (C) Antioxidant related genes SOD2, CAT and GPX1 expression levels were rescued by overexpression of TFAM in NRF1 silenced LGCs. The relative expression levels were normalized to the expression amount of GAPDH. Data are expressed as mean \pm S.E.M. (Student's $t$-test, $n=4),{ }^{*} P<0.05$. 
Table 7 TFAM regulates mitochondrial function in NRF1 suppressed goat LGCs.

\begin{tabular}{|c|c|c|c|c|}
\hline Group & $\begin{array}{c}\text { ATP } \\
(\mathrm{nmol} / \mathrm{mg} \text { pro })\end{array}$ & $\begin{array}{c}\text { CCO } \\
(\mu \mathrm{mol} / \mathrm{min} / \mathrm{mg} \text { pro })\end{array}$ & $\begin{array}{c}\mathrm{Na}^{+}-\mathbf{K}^{+}-\text {ATPase } \\
(\mu \mathrm{mol} \mathrm{Pi} / \mathrm{h} / \mathrm{mg} \text { pro })\end{array}$ & $\begin{array}{l}\mathrm{Ca}^{2+}-\mathrm{Mg}^{2+}-\text { ATPase } \\
(\mu \mathrm{mol} \mathrm{Pi} / \mathrm{h} / \mathrm{mg} \text { pro })\end{array}$ \\
\hline shNRF1 + pEX-4-control & $19.31 \pm 1.72$ & $1.49 \pm 0.15$ & $45.59 \pm 2.13$ & $11.92 \pm 0.79$ \\
\hline shNRF1 + pEX-4-TFAM & $30.14 \pm 2.16^{*}$ & $2.48 \pm 0.09^{*}$ & $72.84 \pm 3.93^{*}$ & $14.83 \pm 2.04$ \\
\hline
\end{tabular}

Data are expressed as mean \pm S.E.M. (Student's $t$-test, $n=4$ ).

In the same parameter, *Values mean significant difference between shNRF1 + pEX-4-TFAM (TFAM overexpression) and shNRF1 + pEX-4-control groups $(P<0.05)$.

ATP, adenosine triphosphate; CCO, cytochrome c oxidase; pro, protein.

levels and impaired mtDNA replication (Lee et al. 2014). Mitochondrial dysfunction resulted in the loss of CCO, increased 8-OHdG level and, subsequently, induced oxidative stress and cell apoptosis (Yang et al. 2016), which are supported by our results. In addition, perturbation of NRF1 expression would disrupt the cellular redox balance, which was consistent with previous research (Zou et al. 2016). Among the antioxidants, GSH is a key player in intracellular redox regulation, and GSH/GSSG ratio is used to evaluate the cellular oxidative stress (Guo et al. 2007). Our findings showed that perturbation of NRF1 expression could disrupt the cellular redox balance, which was consistent with previous research (Zou et al. 2016). It has been reported that superoxide is reduced by SOD to $\mathrm{H}_{2} \mathrm{O}_{2}$, and then reacts with GPx and CAT. These interacting defense mechanisms permit cells to live in an oxidative environment (Devine et al. 2012). Sultana and coworkers (2016) found that hyperglycemia induced by streptozotocin led to mitochondrial dysfunction through generating excessive ROS with diminished antioxidant defense system in heart. Banerjee and coworkers (2016) also reported that loss of C/EBPS increased ionizing radiation and mitochondrial dysfunction, which led to antioxidant defense damage and cell apoptosis. In addition, our previous study showed that abnormal expression of NRF1 led to mitochondrial dysfunction (Zhang et al. 2015). These results suggest that aberrant expression of NRF1 alters the intracellular redox balance by mitochondrial dysfunction in goat LGCs.

TFAM is a key regulator of mitochondrial transcription and replication, whose transcription is regulated by NRF1. The downregulation of TFAM could attenuate the coding capacity of mtDNA and mitochondrial biogenesis (Brenmoehl \& Hoeflich 2013). TFAM silencing resulted in decreased basal oxygen consumption and mitochondrial ATP synthesis (Tsutsui et al. 2009), which is consistent with our study that gain of TFAM could rescue the reduced ATP levels and activity of CCO in NRF1 silenced LGCs. Interestingly, it has been reported that TFAM overexpression successfully increased the ATP content and suppressed cell apoptosis by protecting mtDNA against oxidative damage ( $\mathrm{Xu}$ et al. 2009). In this study, we also found that the ectopic expression of TFAM in NRF1 silenced LGCs could alleviate the apoptosis and oxidative stress of goat LGCs. Moreover, Xu and coworkers (2012) found that the overexpression of TFAM could reverse the mitochondrial dysfunction and inhibit mitochondrial oxidative stress. In this study, we provided further evidences that the overexpression of TFAM in NRF1 silenced goat LGCs could rescue mitochondrial dysfunction induced by NRF1 knockdown. These studies indicate that NRF1 may regulate mitochondrial function via controlling TFAM transcription in goat LGCs, while further studies are needed to elucidate this hypothesis.

In conclusion, this study demonstrates that attenuated expression of NRF1 leads to mitochondrial dysfunction, disrupts the cellular redox balance, impairs steroid synthesis and finally results in GC apoptosis through the mitochondria-dependent pathway. In addition, overexpression of TFAM could restore the steroid synthesis and anti-apoptosis capacity in NRF1 suppressed goat LGCs. These findings provide novel insights into the mechanisms behind mitochondria-dependent GC identity in goat ovaries during follicular atresia.

Table 8 Effects of TFAM on oxidative stress in NRF1 suppressed goat LGCs.

\begin{tabular}{|c|c|c|c|c|c|c|c|}
\hline Group & $\begin{array}{c}\text { 8-OHdG } \\
(\mu \mathrm{mol} \mathrm{Pi} / \mathrm{h} / \mathrm{mg} \text { pro })\end{array}$ & $\begin{array}{c}\text { SOD } \\
\text { (U/mg pro) }\end{array}$ & $\begin{array}{c}\text { CAT } \\
\text { (U/mg pro) }\end{array}$ & $\begin{array}{c}\text { GPx } \\
\text { (U/mg pro) }\end{array}$ & $\begin{array}{c}\text { GSH } \\
\text { (nmol/mg pro) }\end{array}$ & $\begin{array}{c}\text { GSSG } \\
\text { (nmol/mg pro) }\end{array}$ & GSH/GSSG \\
\hline shNR & $3.94 \pm 0.47$ & $8.79 \pm 1.86$ & $4.25 \pm 0$ & $16.92 \pm 2.85$ & $13.21 \pm$ & $1.18 \pm 0.29$ & $11.19 \pm 3.08$ \\
\hline shNRF1 + pEX-4-TFAM & $1.89 \pm 0.39^{*}$ & $12.09 \pm 2.09$ & $9.13 \pm 2.07^{*}$ & $35.84 \pm 3.17^{*}$ & $19.81 \pm 1.72 *$ & $0.97 \pm 0.31$ & $20.42 \pm 2.86^{*}$ \\
\hline
\end{tabular}

Data are presented as mean \pm S.E.M. (Student's $t$-test, $n=4$ ).

In the same parameter, *Values mean significant difference between shNRF1 + pEX-4-TFAM (TFAM overexpression) and shNRF1 + pEX-4-control groups $(P<0.05)$.

8-OHdG, 8-hydroxy-2'-deoxyguanosine; CAT, catalase; GPx, glutathione peroxidase; GSH, reduced glutathione; GSSG, oxidized glutathione; pro, protein; SOD, superoxide dismutase. 


\section{Supplementary data}

This is linked to the online version of the paper at http://dx.doi. org/10.1530/REP-16-0583.

\section{Declaration of interest}

The authors declare that there is no conflict of interest that could be perceived as prejudicing the impartiality of the research reported.

\section{Funding}

This study was financially supported by the National Nature Science Foundation of China (No. 31272443), the China Postdoctoral Science Foundation (No. 80252115) and the Priority Academic Program Development of Jiangsu Higher Education Institutions (280100745113).

\section{Acknowledgements}

The authors thank all the members of Feng Wang's laboratory who contributed to sample collection, and doctor Hong-Yan Sun from UCAS for her technical assistance.

\section{References}

Amsterdam A, Keren-Tal I, Aharoni D, Dantes A, Land-Bracha A, Rimon E, Sasson R \& Hirsh L 2003 Steroidogenesis and apoptosis in the mammalian ovary. Steroids 68 861-867. (doi:10.1016/j.steroids.2003.09.003)

Arakane F, Kallen CB, Watari H, Foster JA, Sepuri NB, Pain D, Stayrook SE, Lewis M, Gerton GL \& Strauss JF 3rd 1998 The mechanism of action of steroidogenic acute regulatory protein (StAR). StAR acts on the outside of mitochondria to stimulate steroidogenesis. Journal of Biological Chemistry 273 16339-16345. (doi:10.1074/jbc.273.26.16339)

Asselin E, Xiao CW, Wang YF \& Tsang BK 2000 Mammalian follicular development and atresia: role of apoptosis. Biological Signals and Receptors 9 87-95. (doi:10.1159/000014627)

Bacsi A, Chodaczek G, Hazra TK, Konkel D \& Boldogh I 2007 Increased ROS generation in subsets of OGG1 knockout fibroblast cells. Mechanisms of Ageing and Development 128 637-649. (doi:10.1016/j. mad.2007.09.005)

Banerjee S, Aykin-Burns N, Krager KJ, Shah SK, Melnyk SB, Hauer-Jensen M \& Pawar SA 2016 Loss of C/EBPdelta enhances IR-induced cell death by promoting oxidative stress and mitochondrial dysfunction. Free Radical Biology and Medicine 99 296-307. (doi:10.1016/j.freeradbiomed.2016.08.022)

Boruszewska D, Sinderewicz E, Kowalczyk-Zieba I, Skarzynski DJ \& Woclawek-Potocka I 2013 Influence of lysophosphatidic acid on estradiol production and follicle stimulating hormone action in bovine granulosa cells. Reproductive Biology 13 344-347. (doi:10.1016/j. repbio.2013.09.004)

Brenmoehl J \& Hoeflich A 2013 Dual control of mitochondrial biogenesis by sirtuin 1 and sirtuin 3. Mitochondrion 13 755-761. (doi:10.1016/j. mito.2013.04.002)

Chiang LL, Chen HC, Lee CN, Chuang KJ, Chen TT, Yeh CT, Wang LS, Lee WH, Lin LY, Tseng HE et al. 2013 Serum protein oxidation by diesel exhaust particles: effects on oxidative stress and inflammatory response in vitro. Chemico-Biological Interactions 206 385-393. (doi:10.1016/j. cbi.2013.10.013)

Choi YS, Kim S, Kyu Lee H, Lee KU \& Pak YK 2004 In vitro methylation of nuclear respiratory factor-1 binding site suppresses the promoter activity of mitochondrial transcription factor A. Biochemical and Biophysical Research Communications 314 118-122. (doi:10.1016/j. bbrc.2003.12.065)
Devine PJ, Perreault SD \& Luderer U 2012 Roles of reactive oxygen species and antioxidants in ovarian toxicity. Biology of Reproduction $\mathbf{8 6}$ 27. (doi:10.1095/biolreprod.111.095224)

Drummond AE 2006 The role of steroids in follicular growth. Reproductive Biology and Endocrinology 4 16. (doi:10.1186/1477-7827-4-16)

Duarte A, Poderoso C, Cooke M, Soria G, Cornejo Maciel F, Gottifredi V \& Podesta EJ 2012 Mitochondrial fusion is essential for steroid biosynthesis. PLOS ONE 7 e45829. (doi:10.1371/journal.pone.0045829)

Ge H, Zhang F, Shan D, Chen H, Wang X, Ling C, Xi H, Huang J, Zhu C \& Lv J 2015 Effects of mitochondrial uncoupling protein 2 inhibition by genipin in human cumulus cells. BioMed Research International 2015 323246. (doi:10.1155/2015/323246)

Glister C, Hatzirodos N, Hummitzsch K, Knight PG \& Rodgers RJ 2014 The global effect of follicle-stimulating hormone and tumour necrosis factor alpha on gene expression in cultured bovine ovarian granulosa cells. BMC Genomics 15 72. (doi:10.1186/1471-2164-15-72)

Grasselli F, Baratta L, Baioni L, Bussolati S, Ramoni R, Grolli S \& Basini G 2010 Bisphenol A disrupts granulosa cell function. Domestic Animal Endocrinology 39 34-39. (doi:10.1016/j.domaniend.2010.01.004)

Guo S, Wharton W, Moseley P \& Shi H 2007 Heat shock protein 70 regulates cellular redox status by modulating glutathione-related enzyme activities. Cell Stress and Chaperones 12 245-254. (doi:10.1379/CSC-265.1)

Jain P, Jain M, Haldar C, Singh TB \& Jain S 2013 Melatonin and its correlation with testosterone in polycystic ovarian syndrome. Journal of Human Reproductive Sciences 6 253-258. (doi:10.4103/09741208.126295)

Kaipia A \& Hsueh AJ 1997 Regulation of ovarian follicle atresia. Annual Review of Physiology 59 349-363. (doi:10.1146/annurev. physiol.59.1.349)

Ke FC, Chuang LC, Lee MT, Chen YJ, Lin SW, Wang PS, Stocco DM \& Hwang JJ 2004 The modulatory role of transforming growth factor beta 1 and androstenedione on follicle-stimulating hormone-induced gelatinase secretion and steroidogenesis in rat granulosa cells. Biology of Reproduction 70 1292-1298. (doi:10.1095/biolreprod.103.023531)

Khalaj L, Nejad SC, Mohammadi M, Zadeh SS, Pour MH, Ahmadiani A, Khodagholi F, Ashabi G, Alamdary SZ \& Samami E 2013 Gemfibrozil pretreatment proved protection against acute restraint stress-induced changes in the male rats' hippocampus. Brain Research 1527 117-130. (doi:10.1016/j.brainres.2013.06.041)

Korsmeyer SJ, Shutter JR, Veis DJ, Merry DE \& Oltvai ZN 1993 Bcl-2/ Bax: a rheostat that regulates an anti-oxidant pathway and cell death. Seminars in Cancer Biology 4 327-332.

Lee HT, Lin CS, Lee CS, Tsai CY \& Wei YH 2014 Increased 8-hydroxy-2'deoxyguanosine in plasma and decreased mRNA expression of human 8-oxoguanine DNA glycosylase 1, anti-oxidant enzymes, mitochondrial biogenesis-related proteins and glycolytic enzymes in leucocytes in patients with systemic lupus erythematosus. Clinical and Experimental Immunology 176 66-77. (doi:10.1111/cei.12256)

Li W, Wu ZQ, Zhang S, Cao R, Zhao J, Sun ZJ \& Zou W 2016 Augmented expression of gamma-glutamyl transferase 5 (GGT5) impairs testicular steroidogenesis by deregulating local oxidative stress. Cell and Tissue Research 366 1-15. (doi:10.1080/03008207.2016.1248287)

Lin P, Yang Y, Li X, Chen F, Cui C, Hu L, Li Q, Liu W \& Jin Y 2012 Endoplasmic reticulum stress is involved in granulosa cell apoptosis during follicular atresia in goat ovaries. Molecular Reproduction and Development 79 423-432. (doi:10.1002/mrd.22045)

Mahmoodi M, Soleimani Mehranjani M, Shariatzadeh SM, Eimani H \& Shahverdi A $2015 \mathrm{~N}$-acetylcysteine improves function and follicular survival in mice ovarian grafts through inhibition of oxidative stress. Reproductive BioMedicine Online 30 101-110. (doi:10.1016/j. rbmo.2014.09.013)

Matsuda F, Inoue N, Manabe N \& Ohkura S 2012 Follicular growth and atresia in mammalian ovaries: regulation by survival and death of granulosa cells. Journal of Reproduction and Development $\mathbf{5 8} 44-50$. (doi:10.1262/jrd.2011-012)

Mattingly KA, Ivanova MM, Riggs KA, Wickramasinghe NS, Barch MJ \& Klinge CM 2008 Estradiol stimulates transcription of nuclear respiratory factor- 1 and increases mitochondrial biogenesis. Molecular Endocrinology 22 609-622. (doi:10.1210/me.2007-0029)

Mizutani T, Ishikane S, Kawabe S, Umezawa A \& Miyamoto K 2015 Transcriptional regulation of genes related to progesterone production. Endocrine Journal 62 757-763. (doi:10.1507/endocrj.EJ15-0260) 
Ohtsuji M, Katsuoka F, Kobayashi A, Aburatani H, Hayes JD \& Yamamoto M 2008 Nrf1 and Nrf2 play distinct roles in activation of antioxidant response element-dependent genes. Journal of Biological Chemistry 283 33554-33562. (doi:10.1074/jbc.M804597200)

Okoh VO, Garba NA, Penney RB, Das J, Deoraj A, Singh KP, Sarkar S, Felty Q, Yoo C, Jackson RM et al. 2015 Redox signalling to nuclear regulatory proteins by reactive oxygen species contributes to oestrogeninduced growth of breast cancer cells. British Journal of Cancer 112 1687-1702. (doi:10.1038/bjc.2014.586)

Piantadosi CA \& Suliman HB 2006 Mitochondrial transcription factor A induction by redox activation of nuclear respiratory factor 1 . Journal of Biological Chemistry 281 324-333. (doi:10.1074/jbc.M508805200)

Piao Y, Kim HG, Oh MS \& Pak YK 2012 Overexpression of TFAM, NRF-1 and myr-AKT protects the MPP(+)-induced mitochondrial dysfunctions in neuronal cells. Biochimica et Biophysica Acta 1820 577-585. (doi:10.1016/j.bbagen.2011.08.007)

Radde BN, Ivanova MM, Mai HX, Alizadeh-Rad N, Piell K, Van Hoose P, Cole MP, Muluhngwi P, Kalbfleisch TS, Rouchka EC et al. 2016 Nuclear respiratory factor- 1 and bioenergetics in tamoxifen-resistant breast cancer cells. Experimental Cell Research 347 222-231. (doi:10.1016/j. yexcr.2016.08.006)

Raisova M, Hossini AM, Eberle J, Riebeling C, Wieder T, Sturm I, Daniel PT, Orfanos CE \& Geilen CC 2001 The Bax/Bcl-2 ratio determines the susceptibility of human melanoma cells to CD95/ Fas-mediated apoptosis. Journal of Investigative Dermatology 117 333-340. (doi:10.1046/j.0022-202x.2001.01409.x)

Sahmi M, Nicola ES, Silva JM \& Price CA 2004 Expression of 17betaand 3beta-hydroxysteroid dehydrogenases and steroidogenic acute regulatory protein in non-luteinizing bovine granulosa cells in vitro. Molecular and Cellular Endocrinology 223 43-54. (doi:10.1016/j. mce.2004.05.010)

Sanchez AM, Somigliana E, Vercellini P, Pagliardini L, Candiani M \& Vigano P 2016 Endometriosis as a detrimental condition for granulosa cell steroidogenesis and development: from molecular alterations to clinical impact. Journal of Steroid Biochemistry and Molecular Biology 155 35-46. (doi:10.1016/j.jsbmb.2015.07.023)

Shabalina IG, Landreh L, Edgar D, Hou M, Gibanova N, Atanassova N, Petrovic N, Hultenby K, Soder O, Nedergaard J et al. 2015 Leydig cell steroidogenesis unexpectedly escapes mitochondrial dysfunction in prematurely aging mice. FASEB Journal 29 3274-3286. (doi:10.1096/ fj.15-271825)

Sultana MR, Bagul PK, Katare PB, Anwar S, Padiya R \& Banerjee SK 2016 Garlic activates SIRT-3 to prevent cardiac oxidative stress and mitochondrial dysfunction in diabetes. Life Science 164 42-51. (doi:10.1016/j.lfs.2016.08.030)

Tosca L, Rame C, Chabrolle C, Tesseraud S \& Dupont J 2010 Metformin decreases IGF1-induced cell proliferation and protein synthesis through AMP-activated protein kinase in cultured bovine granulosa cells. Reproduction 139 409-418. (doi:10.1530/REP-09-0351)
Tsutsui H, Kinugawa S \& Matsushima S 2009 Mitochondrial oxidative stress and dysfunction in myocardial remodelling. Cardiovascular Research 81 449-456. (doi:10.1093/cvr/cvn280)

Wang C, Li Z, Lu Y, Du R, Katiyar S, Yang J, Fu M, Leader JE, Quong A, Novikoff PM et al. 2006 Cyclin D1 repression of nuclear respiratory factor 1 integrates nuclear DNA synthesis and mitochondrial function. PNAS 103 11567-11572. (doi:10.1073/pnas.0603363103)

Xu S, Zhong M, Zhang L, Wang Y, Zhou Z, Hao Y, Zhang W, Yang X, Wei A, Pei L et al. 2009 Overexpression of Tfam protects mitochondria against beta-amyloid-induced oxidative damage in SH-SY5Y cells. FEBS Journal 276 3800-3809. (doi:10.1111/j.1742-4658.2009.07094.x)

Xu S, Chen Y, Lin H, Pi H, Zhang N, Zhao C, Shuai L, Zhong M, Yu Z, Zhou Z et al. 2012 Damage to mtDNA in liver injury of patients with extrahepatic cholestasis: the protective effects of mitochondrial transcription factor A. Free Radical Biology and Medicine 52 1543-1551. (doi:10.1016/j.freeradbiomed.2012.01.007)

Yang Y, Zhou Y, Cheng S, Sun JL, Yao H \& Ma L 2016 Effect of uric acid on mitochondrial function and oxidative stress in hepatocytes. Genetics and Molecular Research 15 gmr8644. (doi:10.4238/gmr.15028644)

Zamzami N \& Kroemer G 2001 The mitochondrion in apoptosis: how Pandora's box opens. Nature Reviews Molecular Cell Biology 2 67-71. (doi:10.1038/35048073)

Zhang Y \& Manning BD 2015 mTORC1 signaling activates NRF1 to increase cellular proteasome levels. Cell Cycle 14 2011-2017. (doi:10.1080/15384101.2015.1044188)

Zhang G, Wan Y, Zhang Y, Lan S, Jia R, Wang Z, Fan Y \& Wang F 2015 Expression of mitochondria-associated genes (PPARGC1A, NRF-1, BCL-2 and BAX) in follicular development and atresia of goat ovaries. Reproduction in Domestic Animals 50 465-473. (doi:10.1111/ rda.12514)

Zhang G, Deng M, Zhang Y, Fan Y, Wan Y, Nie H, Wang Z, Wang F \& Lei Z 2016 Effect of PGC-1 $\alpha$, overexpression or silencing on mitochondrial apoptosis of goat luteinized granulosa cells. Journal of Bioenergetics and Biomembranes 48 493-507. (doi:10.1007/s10863-016-9684-6)

Zou T, Yu B, Yu J, Mao X, Zheng P, He J, Huang Z, Liu Y \& Chen D 2016 Moderately decreased maternal dietary energy intake during pregnancy reduces fetal skeletal muscle mitochondrial biogenesis in the pigs. Genes and Nutrition 11 1-910. (doi:10.1186/s12263-016 -0535-1)

Received 29 October 2016

First decision 16 November 2016

Revised manuscript received 12 May 2017

Accepted 19 May 2017 